\title{
The Sun and solar eclipses in traditional Romanian ornamental patterns
}

\author{
Dimitrie Olenici ${ }^{1}$ and Maria Olenici ${ }^{2}$ \\ ${ }^{1}$ Universitatea "Ştefan cel Mare", \\ Suceava, Str. Universitătii nr. 13A, 72022 Suceava, Romania \\ email: dimitrieolenici@hotmail.com \\ ${ }^{2}$ Complexul Muzeal Bucovina, \\ Str. Ştefan cel Mare, nr. 33, 720003 Suceava, Romania
}

\begin{abstract}
Various ornamental shapes, such as the wheel, the rhombus, the broken cross, and the radiant triangle, which can be seen on popular costumes, domestic objects as well as in architecture, represent solar symbols with a clear apotropaic function whose origins may be detected on the Neolithic clay plates from Jevdet Nasr (Iraq), Knosos (Greece) and Tartaria (Romania). In the North-East of Romania the occurrence of such motifs is extremely frequent especially in traditional architecture. The Triple-Rayed Sun intersected by two lateral arcs is a remarkable adornment of this kind that seems to suggest the representation of an eclipse.
\end{abstract}

Keywords. ancient astral motifs, solar motifs, astronomical signs, myths, symbols

\section{Introduction}

The Sun, as the source of the material and spiritual life of humanity, has deeply influenced human culture and civilisation down through the ages. Symbols which represent the Sun can be found in all the ancient civilisations: Egyptian, Chinese, Indian, Mayan, etc. For example, Mithra the Sun God was worshipped with prayers at the winter solstice, and with a festival at the summer solstice. The ancient Egyptians considered the Sun as being the eye of Horus, which later became the eye of the Lord, and nowadays in a certain style of Christian religious painting this appears as a circle inside a triangle surrounded by rays. In ethnographic studies it is assumed that circles, rings, lozenges, small crosses, and certain other signs found in embroidery, on ceramics, on painted eggs, and used in architectural decoration are representations of the Sun. Moreover, certain more complex images appear to be representations of solar eclipses (Olenici 1999, 2001). The typical example consists of a circle intersected on each sides by a circular arc, with three rays projecting downwards, and with three curves above it. Sometimes another smaller circle can be found in the interior of the circle; sometimes, a small point. To decipher this image which has very ancient roots, it may be said that the circle represents the solar disc, the side arcs the Moon as it passes in front of the Sun, the upper arcs the solar prominences which can be seen during a total eclipse, and the central point a sunspot.

In Romanian villages, similar ornaments are found so often that some houses almost seem to be solar temples of ancient Egypt transferred to our era. This is not accidental. Similar symbols have been seen on a burnt clay tablet discovered in a Tartaria village in Transylvania (Hood 1968). Romanian peasants do not consciously follow Tartaria models when decorating their houses or possessions, but these symbols have descended down through time for six thousand years, from one generation to the next.

Clay tablets like the Tartar ones have been found in Knossos, in Crete, and at Jevdet Nasr in Iraq. Specialists in the field consider the symbols on these tablets as being the first form of human writing. 
Initially, these symbols were put on houses or equipment both for artistic reasons and to serve as a protective talisman. Only the artistic aspect has persisted down to our times. In the Christian world the cross became the protective symbol, and this itself is an ancient representation of the Sun. Over time these symbols have become modified to such an extent that sometimes it is not easy to distinguish the solar eclipse underlying what superficially appears to be a bunch of flowers or a magnificent ornamented cross. Our days, many of this old houses are replaced by modern buildings and this patrimony cultural values risk being lost. For this reason urgent research and conservation actions are imposed. This old monuments of traditional art can be included in astro-tourism networks.

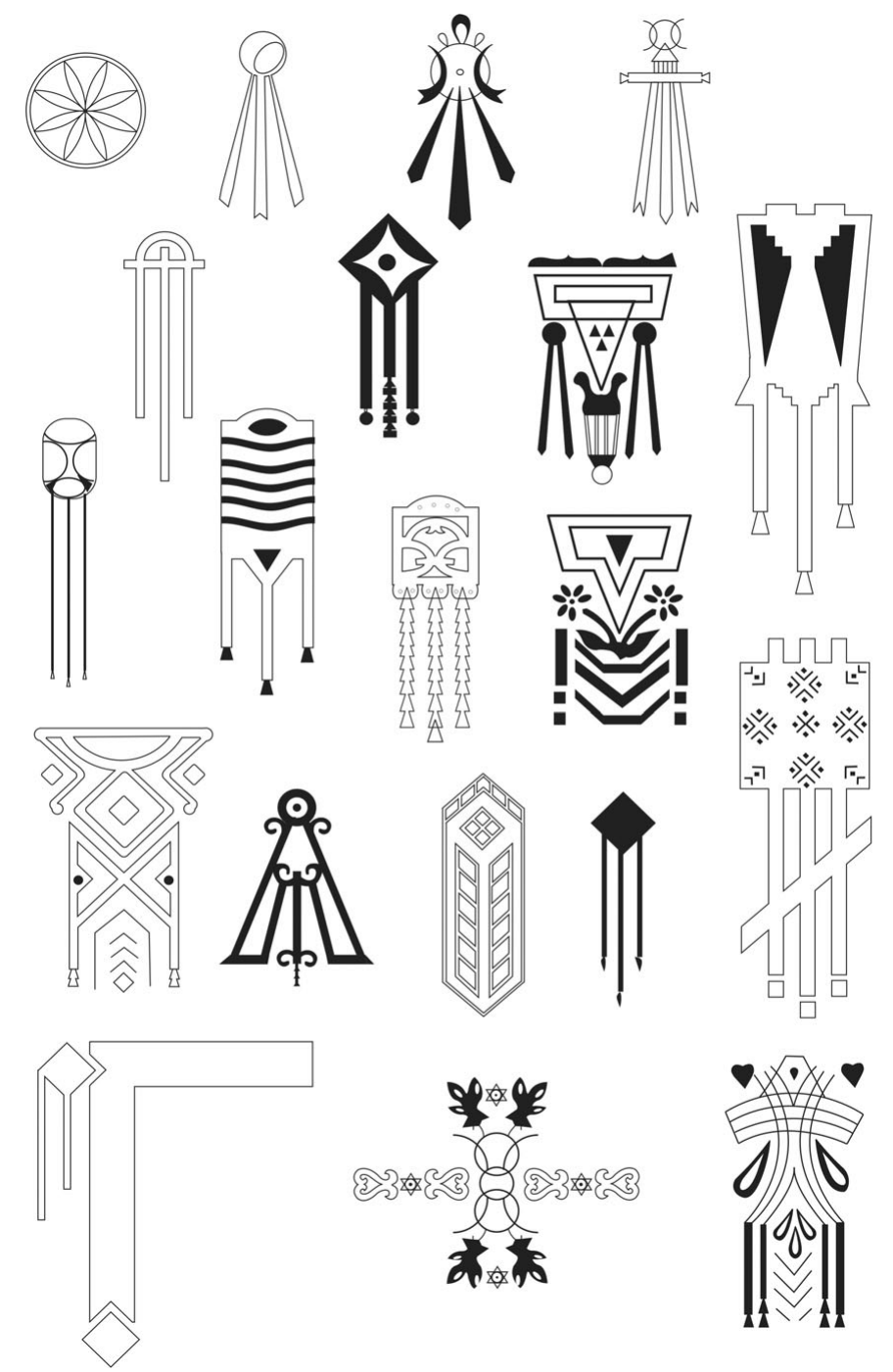

Figure 1. Stylised eclipse motifs in traditional ornaments.

In this contribution we present a small part of the huge collection of Romanian solar symbols maintained at Suceava Planetarium. The following images show various representations of the Sun and solar eclipses. 

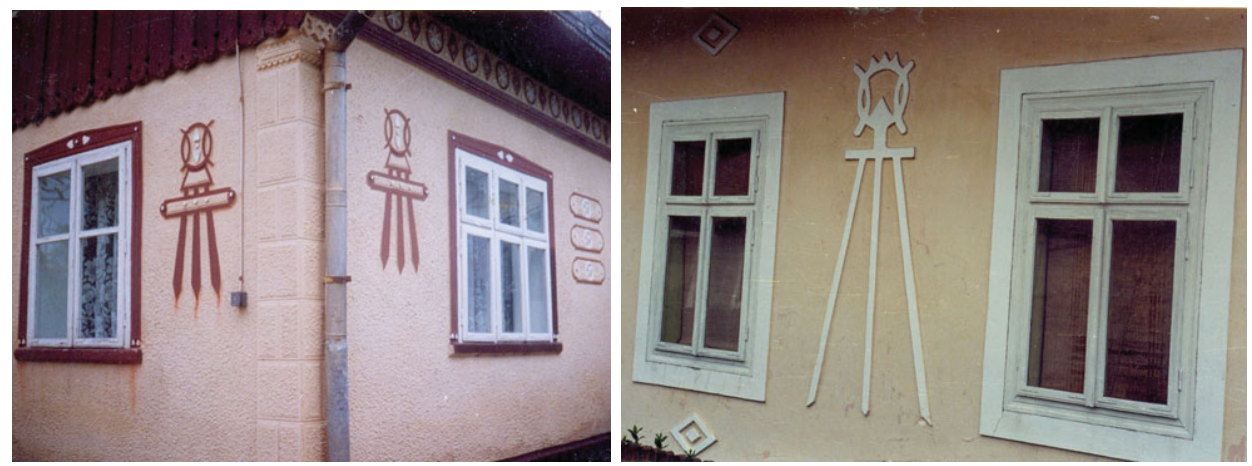

Figure 2. Solar eclipse motifs.
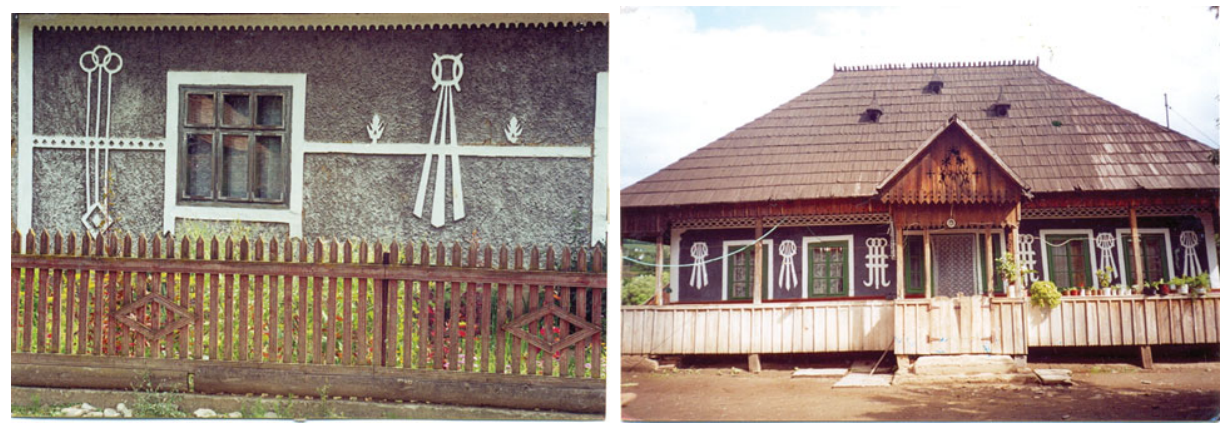

Figure 3. (Left) Multiple suns, the three of life, the horizon and a solar eclipse motif. (Right) A house with motifs of solar eclipses that looks like an ancient solar temple.
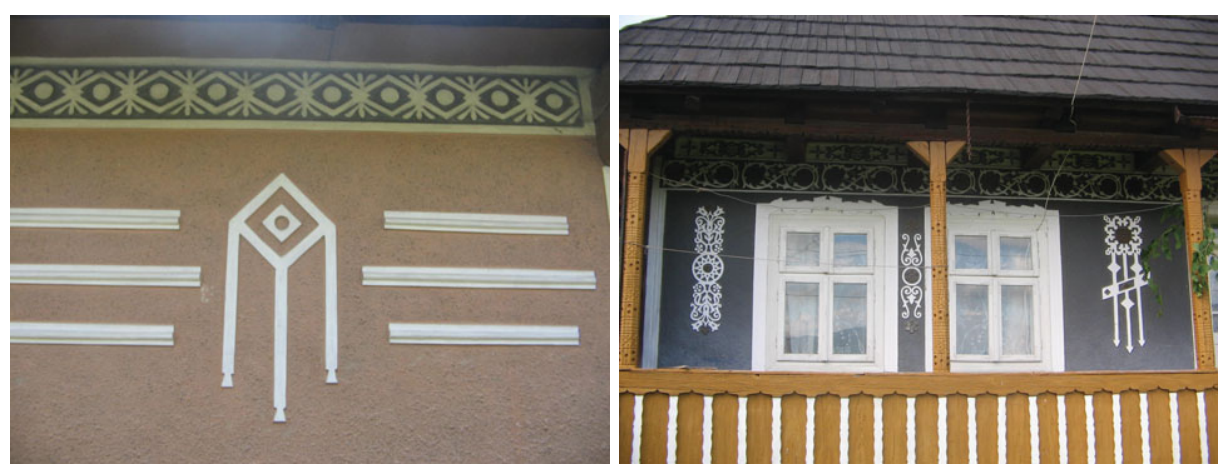

Figure 4. (Left) The Sun as the divine Eye that heals and protects. (Right) The Sun, the Divine Eye and a solar eclipse symbol on a facade of a house.

\section{References}

Hood, M.S.F. 1968, Scientific American, 218, 30

Olenici, D. 1999, Eclipsele de când lumea Soarele şi Luna (Suceava: Editor Casa Corpului Didactic)

Olenici, M. 2001, Făt Frumos, 3, 77 

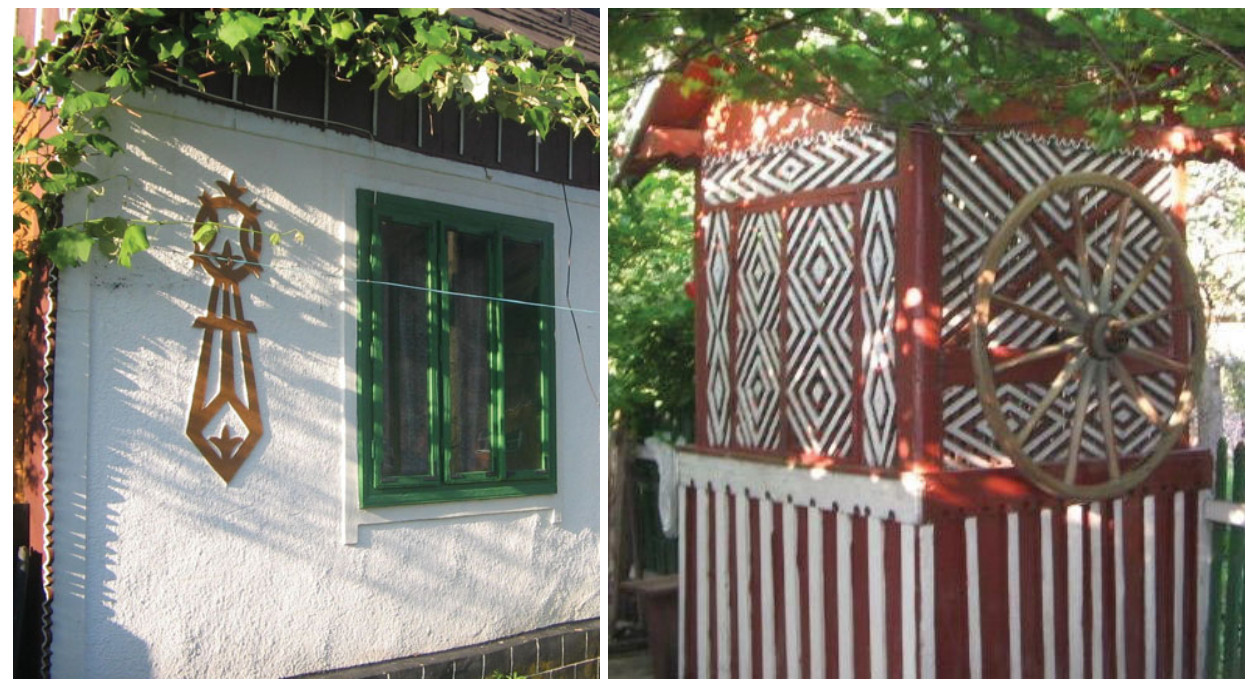

Figure 5. The solar eclipse motif by a window (Left) and on a fountain (Right).
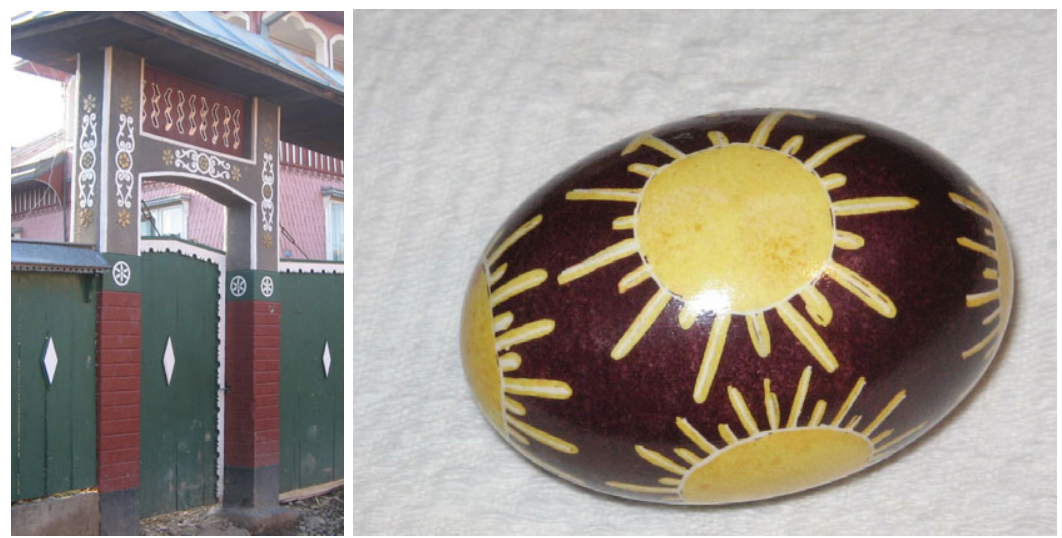

Figure 6. Solar symbols on gateposts (Left) and on a traditional painted Easter egg (Right).
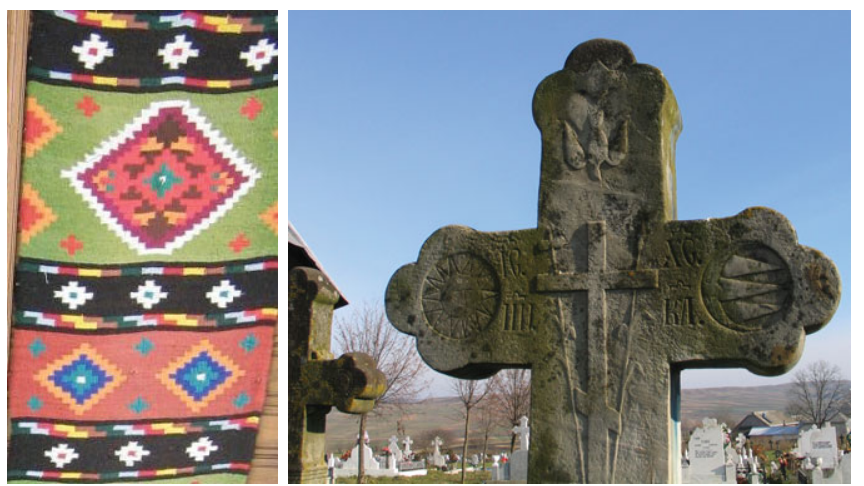

Figure 7. (Left) The Sun stylised on a handcrafted wool carpet. (Right) The Sun and the Moon on a funeral monument. 